\title{
Environmental Performance Evaluation of Polycarbonates Production Processes
}

\author{
Altuwair IB* \\ Faculty of Engineering, Northern Border University, Arar, Saudi Arabia
}

\begin{abstract}
The chemical industrial processes with their energy-intensive production methods and unpleasant image have become "business as usual". Polycarbonate (PC) is one example of energy intensive methods that has become one of the largest industrial processes. Moreover, a large number of hazardous chemicals are used throughout its manufacturing stages. This study is concerned with environmental aspects of PC production. It investigates life cycle based environmental performance evaluation of supercritical fluid (SCF) Application to PC production, more specifically in i) Environmental performance assessment of SFC as chlorinating alternative and ii) Environmental performance assessment of plasticizing scenario as stabilizing step in the PC production. The advantages of using SCF are tied to the cleaner aspects of the technology, minimisation of raw materials and energy demand, reduction of emissions and effluent discharge into the environment and maximisation of environmental benefits. Environmental performance of polycarbonates production by SCF was compared with that of traditional production methods. It was observed that supercritical fluid technology has an impact on the emissions reduction compared with traditional methods. This research contributes to understanding the challenges that the industry of polycarbonate production will face in the future where the chemical emissions are increased resulting from production and energy consumptions.
\end{abstract}

Keywords: Polycarbonate; Industrial process; Emissions; Supercritical fluid; Environmental performance

\section{Introduction}

Industrial emissions have become a global issue due to their irreversible environmental damage. Production of polycarbonates or the so-called plastics is major source of industrial emissions. A major concern with the use of polycarbonate is its overwhelming increase in use. Furthermore, the accelerating environmental consciousness of individual, companies and government entities serves as a driver for polycarbonates or plastics makers to focus attention on the environmental performance of their operations. Environmental consideration should be integrated into process design, regarded as a first step on the path to continuous environmental improvement.

The industrial improvement can be made by performing evaluation method (PEM) based on the environmental impact categories. The PEM is used to compare between alternative processes performances with established standards depends on their productivity.

The productivity improvement by using life cycle assessment (LCA) or "Cradle to Grave" analysis which has emerged as a powerful analytical tool for environmental performance evaluation [1]. It is a method to assess the environmental burdens based on energy and materials used as well as emissions into the environment [2]. Analysing operations processes by performing LCA can increase the productivity and determine the energy consumption and related wastes. Richard el al. presented the link between environmental chemicals and adverse effects on human health [3]. In addition, Zhang has presented a methodological comparison by using LCA and Risk Assessment to identify and assess chemicals [4]. The environmental degradation and human health risk associated with release emissions due to for instance, energy consumption results from operational processes and utilities were observed. For example, the production of PC has several stages such as Chlorination, Oxy-Chlorination, and Vinylation. Each stage consumes different energy levels which result in different levels of emissions. For instance, Chlorination stage that account for large energy consumption and waste released. It emits chlorinated hydrocarbons which have negative effects on the environment and human health. Using environmental evaluation tool In order to evaluate the environmental impact is necessary. Life cycle analysis LCA can be used as an analytical tool to convert chemical emissions into quantitative risk and evaluate the environmental impact of a particular technology.

LCA is a four-stage process including:

(1) Scoping,

(2) Inventory Analysis,

(3) Impact Assessment, and

(4) Interpretation and Improvement.

1. Scoping: Defines the extent of analysis and the system boundaries;

2. Inventory Analysis: Documents material and energy flows which occur within the system boundaries (also called the life cycle inventory or LCI);

3. Impact Assessment: Characterizes and assesses the environmental impacts using the data obtained from the inventory also called the life cycle impact assessment (LCIA); and

4. Interpretation and Improvement: Modification and improvement to reduce the environmental burden throughout the product's life based on the results of inventory and impact stages (Figure 1).

This study covers an environmental performance evaluation for the production of polycarbonates (PC). Based on Association of the

*Corresponding author: Ibrahim Abdullah Altuwair, NFaculty of Engineering, Northem Border University, Arar, Saudi Arabia, Tel: 17097704044; E-mail: iaa134@mun.ca

Received March 23, 2017; Accepted April 25, 2017; Published April 30, 2017

Citation: Altuwair IB (2017) Environmental Performance Evaluation of Polycarbonates Production Processes. Ind Eng Manage 6: 214. doi:10.4172/2169-0316.1000214

Copyright: @ 2017 Altuwair IB. This is an open-access article distributed under the terms of the Creative Commons Attribution License, which permits unrestricted use, distribution, and reproduction in any medium, provided the original author and source are credited. 
Dutch Chemical Industry (VNCI), Netherlands, 2001, environmental performance evaluation (EPE) used to assess environmental performance and identify areas for improvement that enables industry to evaluate the environmental performance.

The aim of this paper is to apply an environmental performance evaluation for PC production methods and define the parameters that influencing or/and stimulating the production throughout the life cycle of each stage. This helps to find an effective way for improving the process operation and reduce the adverse impact on both human health and environment.

The lack of information result in the uncertainty of environmental index that limit accuracy and credibility of the results, thus errors are expected.

\section{Literature Review}

Emissions results from PC production have become an issue due to the different ratio of inputs consumed to outputs achieved. The less emissions output for a given input, the better efficiency will be achieved [5]. It has been observed by Khan and sadiq that the optimization of industrial process, which refers to find the best solution from all feasible solutions, increases the overall environmental burden and impacts. Thus, systematic and reliable tools are necessary to assess environmentally the productivity performance.

Cave and Edwards studied the industrial processes impact and design process improvement [6]. They have noticed that methods are lacking for assessing chemical process for environmentally friendly.

Khan presented a new life cycle indexing system which considered a number of basic parameters for a complete life cycle assessment for a proposed process. Niels investigated and compare environmental impacts of production process. Xu has adopted an LCA perspective to analyze and reduce greenhouse gas (GHG) emissions in chemical industry. Tonopool et al. used LCA method to find out how to improve environmental performance of industry.

Established guidelines for performing detailed LCAs are well documented by the Environmental Protection Agency (EPA), Society for Environmental Toxicologists and Chemists (SETAC), and the International Organization for Standardization (ISO) [7]. As defined by the ISO 14040 series.

LCAs have typically focused on total energy usage, including energy required to operate the production process as well as energy embodied in the production materials. There are studies which have examined waste generation and health-related air pollution, or expanded the scope to include construction impacts [8-10]. Azapagic et al. have proposed a methodology as shown in Figure 1 for process design based on the life cycle assessment.

LCAs provide information on which stage of production (production, use, or disposal) causes the most environmental impact and may offer suggestions to minimize those burdens. Although various productions processes performance have been evaluated by LCA applications, uncertainity associated with the assumptions needs to be considered [11].

Shokravi et al. Proposed environmental performance evaluation method and find the parameters that have adverse impacts on its results [12]. This describes the relationship between the production process and environment in order to mitigate the environmental impact.

In addition, environmental performance evaluation of industrial process has attracted researchers' attentions. Lin and Polenske applied a process-level input-output model based on reported process data to illustrate how changes in manufacturing process can affect environmental aspects. Lainexay presented environmental standards, specifically these related to air pollution, emissions, and air quality. Xiu et al. has studied and analyzed pollutants associated with industrial process [13]. An Environmental performance evaluation method for a purpose of comparison to improve the outcomes of the productivity and modified design method for polycarbonate production will be analyzed with the help of chosen example (Figure 1).

\section{Polycarbonate production process}

Polycarbonate is produced by the reaction of phosgene with bisphenol A. Phosgene is produced by reacting chlorine from the electrolysis of sodium chloride with carbon monoxide produced by the pyrolysis of coal, oil or gas.

The production route for bisphenol A is more complex. Natural gas is subject to cracking to produce cumene. Finally, the phenol and acetone, as a result of cumene production, are reacted to produce bisphenol A BPA. The BPA reacts with DPC leading to polycarbonate. The overall process of $\mathrm{PC}$ described as follows:

Cumene (Raw Material) $\rightarrow$ Acetone $\rightarrow$ Bisphenol A $\rightarrow$ Polycarbonates (Product)

\section{System boundary of production}

The system boundary shows the process of life cycle assessment for PC. There are four stages: Raw material, Manufacturing, Use, Recycle, and Disposal (End life of the Product). The manufacturing stage will be the focus of study. The following figure describes it in more details (Figures 2 and 3 ).

The production process describes the production stages of PC. The focus of the PC production is on the blow moulding (bounded by dot lines) where toxic materials are used such as stabilizers, fillers and plasticisers. The material balance during the production stage explains the energy consumed and required material. During manufacturing stage, crude oil is required to produce naphtha which is leading to

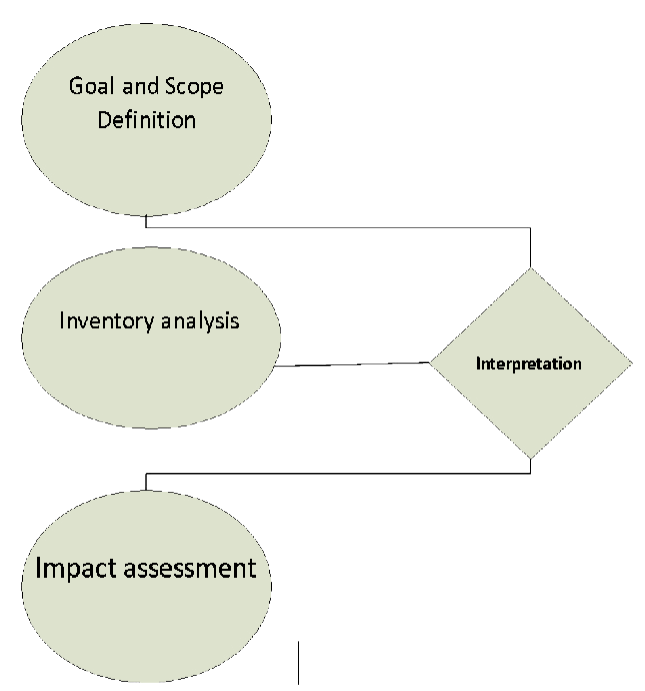

Figure 1: Methodological framework for life cycle assessment, revised (UNEP). 
ethylene and p-xylene productions. These chemicals are necessary for ethylene glycol and teraphthalic acid production during polymerization stage. After polymerization, the mixture of the product as compound is made. Then a blow moulding is used to formulate the product and final product is packed.

\section{Traditional process}

There is a traditional production method for polycarbonate PC:

Phosgene process: Figure 4 shows the most common manufacturing polycarbonate processes by the reaction of Bisphenol A BPA with Phosgene $\mathrm{COCl}_{2}$ in the interfacial polymerization.

$$
\mathrm{COCl}_{2}+\mathrm{BPA} \rightarrow \mathrm{PC}
$$

Process Phases

$$
\begin{aligned}
& \mathrm{C}_{2} \mathrm{H}_{4}+\mathrm{Cl}_{2} \rightarrow \mathrm{C}_{2} \mathrm{H}_{4} \mathrm{Cl}_{2} \text { (EDC) (Chlorination Step) (1) } \\
& \mathrm{C}_{2} \mathrm{H}_{4} \mathrm{Cl}_{2} \text { (EDC) } \rightarrow \mathrm{C}_{2} \mathrm{H}_{2} \mathrm{HCl}+\mathrm{HCl} \text { (Pyrolysis Step) (2) } \\
& \mathrm{C}_{2} \mathrm{H}_{4} \text { (Cracking) } \rightarrow \mathrm{CH}_{2}=\mathrm{CHCl}+\mathrm{HCl} \text { (Vinylation Step) (3) }
\end{aligned}
$$

Ref: Sources: Industrial Chemical Division, Canadian Oxy, 2006 IPCC, and Castro, Jablansky, Lee, and MacMillan "New Phosgene-Free Route To Polycarbonate", April 2013.

Environmental problems: Phosgene was an essential for PC production. It consists of chlorine and carbon monoxide as follows:

$$
\mathrm{CO}+\mathrm{Cl}_{2} \rightarrow \mathrm{COCl}_{2}
$$

Nowadays, the production and use of phosgene in the factories have been very severely restricted worldwide. The needs of bisphenol $A$ and the complexity and danger of the process have drawn the attention of scientists and researchers for a long time due to the yield of undesirable by-products remained at high level of $150-200 \mathrm{~kg} / \mathrm{t}$ of phenol (Figure 5).

\section{Free-phosgene process}

The traditional production method based on phosgene shows high risk due to highly toxic materials associated with phosgene $(\mathrm{COCl})$. However, Alternative method presented by Fabiano described a better way for PC production by getting rid of phosgene and producing diphenyl carbonate (DPC). Although the new method is slower than traditional method, it presents emissions reduction. In addition Castro mentioned that this process also economically more effective method (Figure 6) [14]. (PC)

Diphenylecarbonate $(\mathrm{DPC})+$ Bisphenol A $(\mathrm{BPA}) \rightarrow$ Polycarbonate

Figure 5 describes an alternative way of polycarbonate production by diphenyl carbonate DPC.

\section{Production processes drawbacks}

The phosgene process has a number of drawbacks including the toxicity of phosgene, the use of low-boiling-point solvent, and the large quantity of waste containing chlorinated hydrocarbons which must be treated. The use of concentrated sodium hydroxide and hydrogen chloride creates several problems to the processing production of polycarbonates which should be considered such as corrosion, health problem, and environmental damage. Although non-Phosgene process has lower cost than traditional process (phosgene route), there are some disadvantages associated with it such as the high temperatures and high vacuum generated by the operations. However, it is anticipated that this kind of non-phosgene process will be widely adopted for PC production throughout the world.

\section{Comparison of production methods}

The traditional production methods of polycarbonates PC are divided into two routes: Phosgene and non-Phosgene routes. Comparison between the two methods based on their impacts on the human health and environment atmosphere is studied and presented as follows (Table 1).

The table shows the safety hazards associated with each PC production method (phosgene route and the free phosgene routes).

In addition, the probability of human health risk due to the Phosgene route for polycarbonate production is higher than the phosgene-free route due to:

1. The process design describes the way of producing the PC by two routes. Phosgene needs BPA in order to complete the process reaction. The BPA is indirectly produces by the reaction of phenol with acetone whereas free-phosgene route has directly producing the PC by phenol with carbon monoxide.

2. The number of process stages in the phosgene-free route is less than that in the phosgene route.
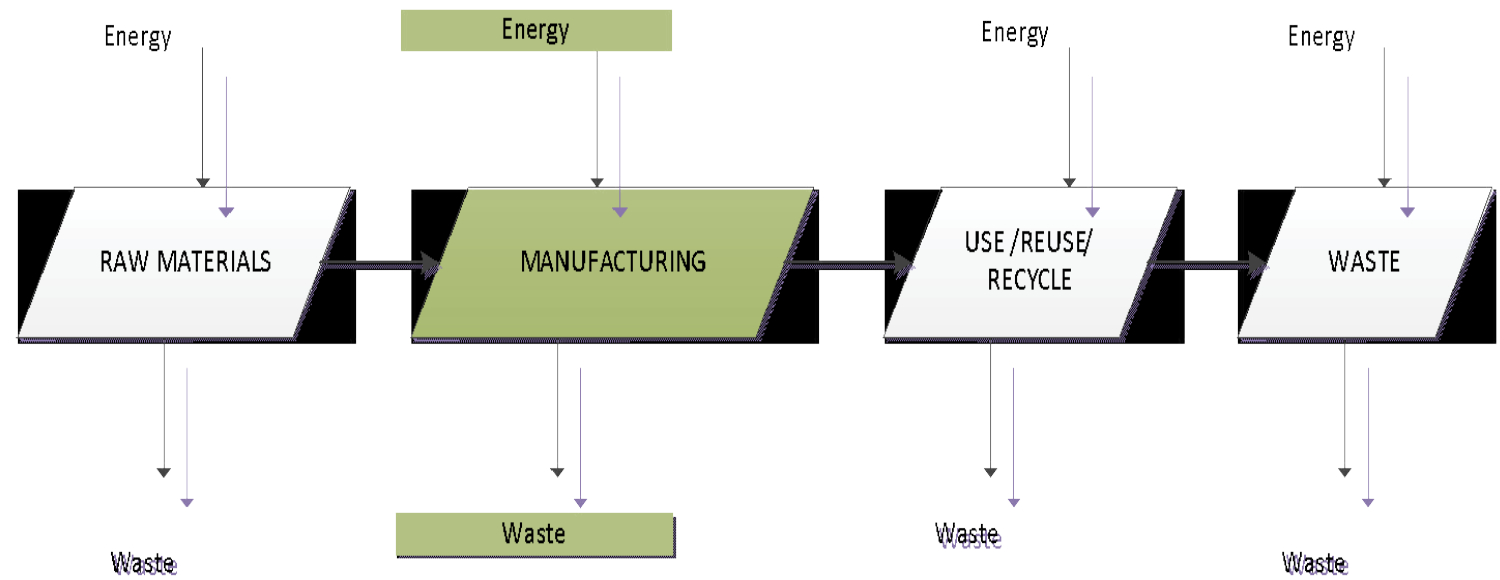

Figure 2: System boundary. 


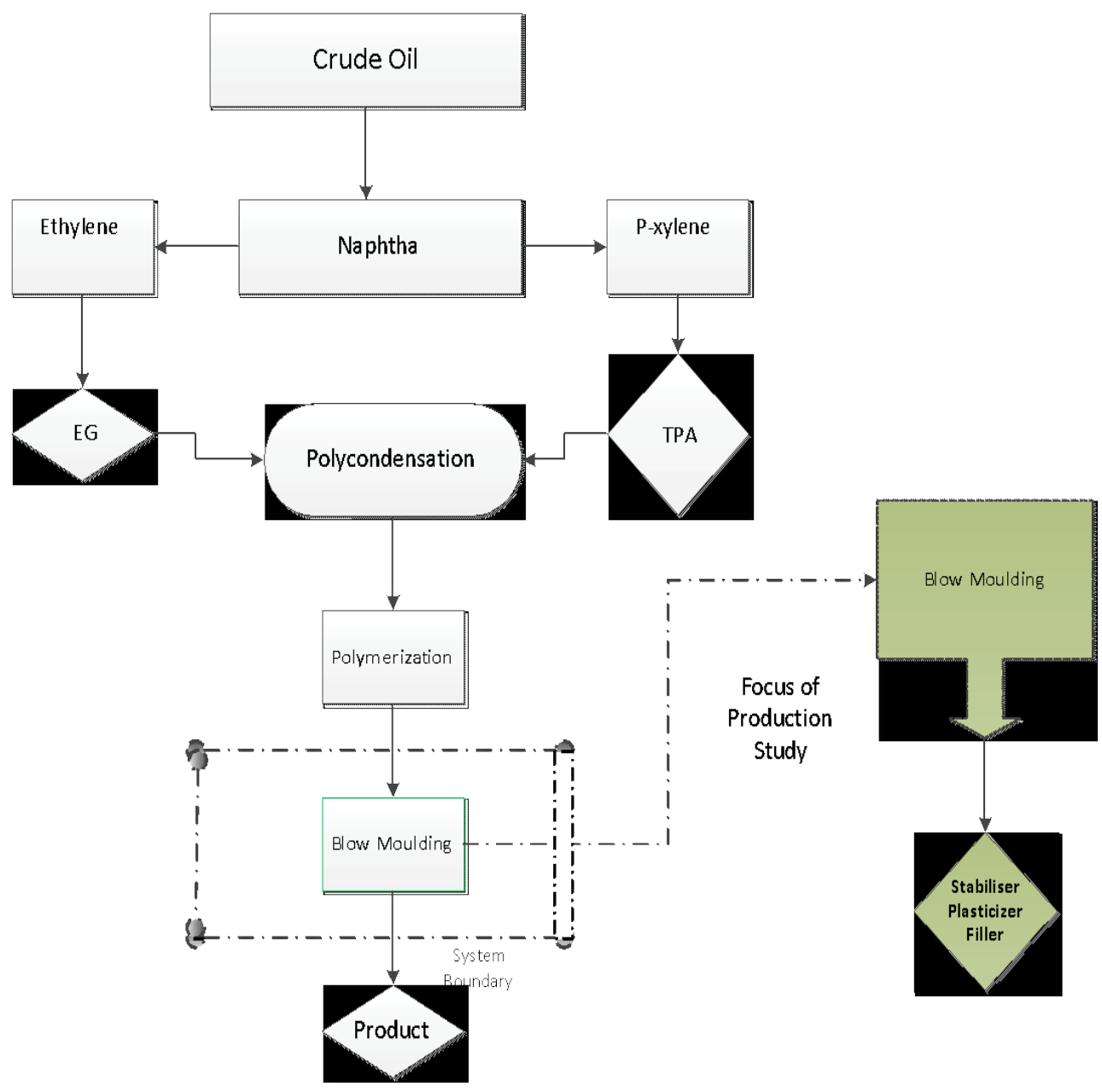

Figure 3: Production phase of polycarbonate.

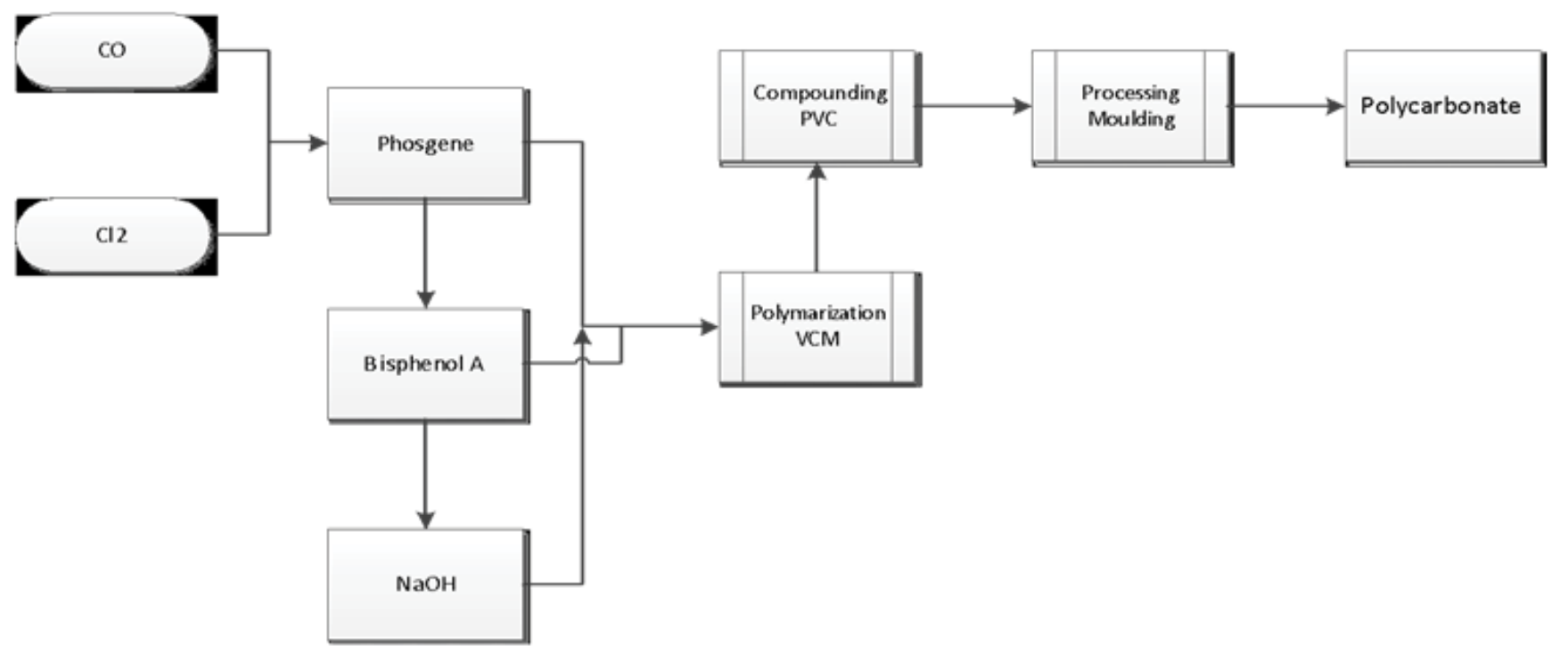

Figure 4: Phosgene process. 


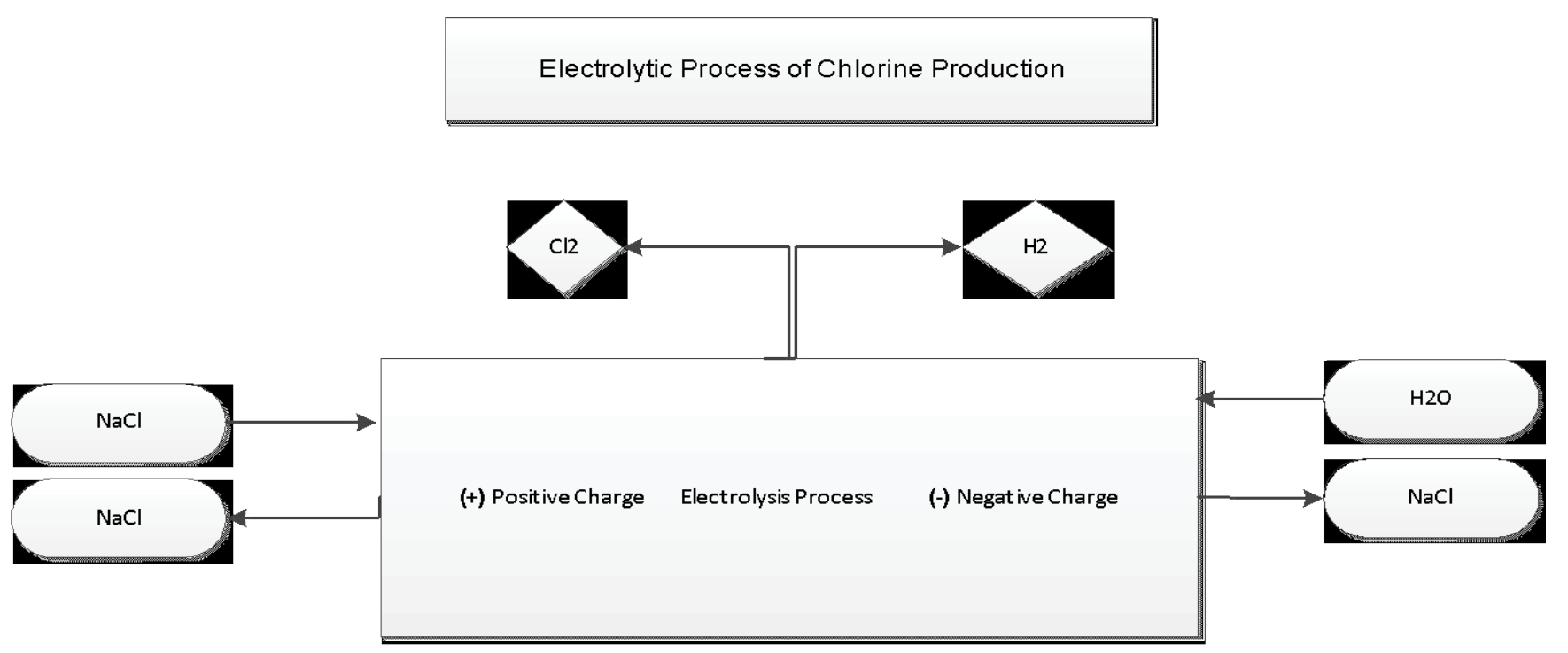

Source"Ch loralkali Electrolysis" .((Adopted), Bommaraju, TilakV ; Orosz, PaulJ.; Sokol, Elizabeth A . (2007), Archived 31-10-2009)

Figure 5: Electrolytic process of chlorine production.

\begin{tabular}{|c|c|c|}
\hline Description & Process Route 1 & Process Route 2 \\
\hline Process Description & Phosgene & Non-Phosgene \\
\hline Process Design & Indirect Reaction Process (BPA-PC) & Direct Reaction Process (Phenol-CO) \\
\hline Process Stages & Many Process Stages & Less Process Stages \\
\hline Acidity & High acidic materials & Low acidic materials \\
\hline Process Outputs & Sodium Chloride NaOH Low Conversion & Base Catalysts \\
\hline Catalyst Options & High & Low CO High conversion \\
\hline Environmental Impact & High & Low \\
\hline
\end{tabular}

Table 1: Comparison of PC production methods.

3. Toxicity level is significant in phosgene route due to the harmful and corrosive materials used throughout the production stages [15].

4. Increasing the risk likelihood of illness or death associated with phosgene route due to toxic by-products, however, with the phosgene-free process, has less impact on human health and environment than traditional phosgene route.

5. Finally, the risk associated with the phosgene method is higher than the phosgene-free method and also more costly due to the higher energy consumption.

Although the phosgene-free process is environmentally and economically is reliable, it is slow.

\section{Research Methodology}

The strategy of the research based on theoretical analysis for comparison and evaluation of environmental performance for different polycarbonate production methods. To describe the environmental Impact developed by a particular method or process, the Life cycle based environmental performance evaluation for supercritical fluid application on polycarbonate production methodology will be evaluated based on:
- Life cycle analysis

- Environmental Performance Assessment

- Environment category Indicators

To obtain environmental information during the polycarbonate manufacturing process, a quantitative analysis of environmental performance is highlighted. The method presented in this paper seeks to look at the overall environmental performance, and identify what action to be taken to make a decision. The most common procedure, a deterministic and scenario based approach, is that specific scenarios are chosen from the environmental risk assessment of the process industry. It includes aspects such as type of agent, type of population, location, etc. The resulting scenarios contain information on possible emission source, geometry, etc. A major item in exposure scenarios is the choice of the so-called design process operation production of polycarbonate, which will be discussed below. These scenarios allow us to compare between designated processes and how changes help to improve alternative method for future challenges. The method consists of the steps of classifying, characterizing, and quantifying the environmental data as given in Figure 7.

The study presents a new processing method for polycarbonate production which environmentally friendly. It is a combination of 
the traditional process with supercritical process. Consequently, a comparison based on the available data and results will be illustrated and a decision will be made based on each process results.

\section{Life cycle analysis}

The methodology uses LCA throughout the design process; thereby environmental consideration has been incorporated from the Production design stage (Figure 1). The analysis of life cycle introduces the process selection based on the optimization of environmental objective, which includes performance and materials and apart from the economic. The system boundary of this study has focused on the most toxic point source where the likelihood of emissions is exceeded the tolerable level (Figure 3). The limitation of the assessment is that the optimization of a large number of criteria is practically very difficult and would result in a tremendous computational load. As all criteria cannot be given higher importance, therefore, Complexity associated with optimization may increases the complexity without noticing improvement in the results. This study will be selecting particular environmental indicators to evaluate each method productions of PC on the environment. A similar approach of integrating LCA with the traditional process design framework has been proposed by Sutherland et al. [16].

\section{Environmental performance assessment}

Environmental evaluation consists of process description, hazard or chemical identification, scenario identification to measure the impact or severity and the probability of occurrence (Figure 7).

The first step of the assessment shown in Figure 7 describes a process theoretically based on environmental performance. Classifying data by properly selected and organized into correct categories. Characterizing by model the selected inventory data to provide better perspective than simple mass and quantifying hazard based on the material balance to identify or measure the hazard associated with each precursor or chemical explained in the following sections. Finally, an integrated environmental impact is obtained by applying life cycle analysis (LCA) in order to evaluate the performance of each processing method. Furthermore, modified process based on the results and the influence of method will be taken as a feedback for the changes and improvement.

The procedures systematically and identically help to better identifying each pollutant. It is useful for all comparisons, including judgments of environmental performance

Process description: Any industrial process consists of chemical, physical, and mechanical steps. The study selected and analyzed the process of PC by classification, Hazard Identification, and Evaluation based on the impact categories as follows (Table 2).

The goal of this section is for characterizing the environmental parameters. The general categories are: Global Warming (GW), Ozone Depletion (OD), Acidification Potential (AP), Photochemical Oxidation (PO), and Eutrophication (EU). At the next level the environmental parameters divided according to the type of precursor. At the final level, the environmental performance evaluation based on the environmental parameters stimulated by the type of precursor will be determined by assessing the magnitude of impacts for each of the stressor in order to convert LCA into impact categories Table 1.

\section{Environmental indicators}

Eco-indicator 99 was used in this research. It is developed under the Dutch NOH program. It only takes account of the effects. However, the variation of some indicators between 0 and 1 might be a source of uncertainty.

\section{Modification Process Diagram}

\section{Process production stages}

The process of EDC and VCM production during three stages, Chlorination, Oxy-Chlorination, and Vinylation steps is modified by supercritical fluid SCF (Figures 8 and 9).

$$
\begin{aligned}
& \mathrm{C}_{2} \mathrm{H}_{4}+\mathrm{Cl}_{2} \rightarrow \mathrm{C}_{2} \mathrm{H}_{4} \mathrm{Cl}_{2} \text { (EDC) (Chlorination Step) } \\
& \mathrm{C}_{2} \mathrm{H}_{4} \mathrm{Cl}_{2}(\mathrm{EDC}) \rightarrow \mathrm{C}_{2} \mathrm{H}_{2} \mathrm{HCl}+\mathrm{HCl} \text { (Pyrolysis Step) } \\
& \mathrm{C}_{2} \mathrm{H}_{4}(\mathrm{Cracking}) \rightarrow \mathrm{CH}_{2}=\mathrm{CHCl}+\mathrm{HCl} \text { (Vinylation Step) } \\
& \mathrm{C}_{2} \mathrm{H}_{4}+\mathrm{Cl}_{2}+\mathrm{SCF} \rightarrow \mathrm{SCF} \rightarrow \mathrm{C}_{2} \mathrm{H}_{4} \mathrm{Cl}_{2}(\mathrm{EDC}) \rightarrow \mathrm{SCE} \mathrm{CH}_{2}=\mathrm{CHCl} \\
& (\mathrm{VCM}) \text { (Figure 10). }
\end{aligned}
$$

Supercritical fluid carbon Dioxide $\left(\mathrm{SC}-\mathrm{CO}_{2}\right)$ effectively extracts residual monomer such as DIDP, DOP, and TOTM plasticizers from polycarbonate. It is environmentally friendly methods. Approximately $20-60 \%$ of the production reduction will be achieved by the SCF [17]. The extent (wt\%) of the plasticizer extractions per unit area of the sample determine by dividing the extraction fraction as follows:

$$
[((\mathrm{W} 0-\mathrm{W} 1)(100+\mathrm{X}+6.5)) / \mathrm{W} 0 \mathrm{X}] * 100 \%
$$

\section{W0 is the sample weight before extraction}

$\mathrm{W} 1$ is the sample weight after extraction and $\mathrm{CO}_{2}$ removal

$\mathrm{X}$ is the amount of plasticizer used such as (DOP, DR, DIDP, and TOTM).

The energy consumption and emission releases were reduced by SCF compared to phosgene and non-phosgene processes. Therefore, the probability of environmental impact associated with the supercritical fluid is lower due to reducing the reduction of environmental indicators impacts such as Ozone depletion potential (ODP).

\section{Advantages of the Supercritical Fluid Carbon Dioxide $\mathrm{SC}-\mathrm{CO}_{2}$ Technology}

Supercritical fluids have been used effectively for many industrial productions. It is highly compressed gases, which combine properties of gases and liquids in an intriguing manner.

It can lead to reactions, which are difficult or even impossible to achieve in conventional solvents. Supercritical fluids have solvent power similar to light hydrocarbons for most of the solutes. However, fluorinated compounds are often more soluble in supercritical $\mathrm{CO}_{2}$ than in hydrocarbons; this increased solubility is important for polymerization. It increases with increasing density (that is with increasing pressure). Rapid expansion of supercritical solutions leads to precipitation of a finely divided solid. This is a key feature of flow reactors.

The fluids are commonly miscible with permanent gases (e.g. $\mathrm{N}_{2}$ or $\mathrm{H}_{2}$ ) and this leads too much higher concentrations of dissolved gases than can be achieved in conventional solvents. It can be easily recycled and chemically inert. Other important safety features of using supercritical technology such as: Non-flammable has good solvent characteristics for non-polar and slightly polar solutes. It is a "natural" substance, present in mineral waters and part of the life cycle. It is easily removed from the product. The dissolving power and selectively can be 
Citation: Altuwair IB (2017) Environmental Performance Evaluation of Polycarbonates Production Processes. Ind Eng Manage 6: 214. doi:10.4172/2169-0316.1000214

Page 7 of 11

\begin{tabular}{|c|c|c|c|}
\hline Parameters & Type of Precursors & Traditional Score & Alternative Score \\
\hline Global Warming Potential GWP & $\mathrm{CO}_{2}, \mathrm{NO}_{2}, \mathrm{CH}_{4}, \mathrm{CFC}, \mathrm{CH}_{3} \mathrm{Br}$ & 1 & 1 \\
\hline Ozone Depletion Potential ODP & $\mathrm{Halons}, \mathrm{NOx}, \mathrm{VOC}, \mathrm{SO}_{2}$ & 1 & 0 \\
\hline Photochemical Oxidation POCO & $\mathrm{SO}_{2}, \mathrm{HCl}, \mathrm{NOx}, \mathrm{VOC}, \mathrm{CFC}$ & 1 & 1 \\
\hline Acidification & $\mathrm{HF}, \mathrm{Halons}, \mathrm{SO}_{2}, \mathrm{HCl}$ & 1 & 1 \\
\hline Eutrophication & $\mathrm{P}, \mathrm{N}, \mathrm{PO}_{4}, \mathrm{NH}_{4}, \mathrm{NOx}$ & 1 & $14,11,13,14]$ \\
\hline
\end{tabular}

Table 2: Environmental impacts of traditional and supercritical fluid SCF technology for polycarbonate.

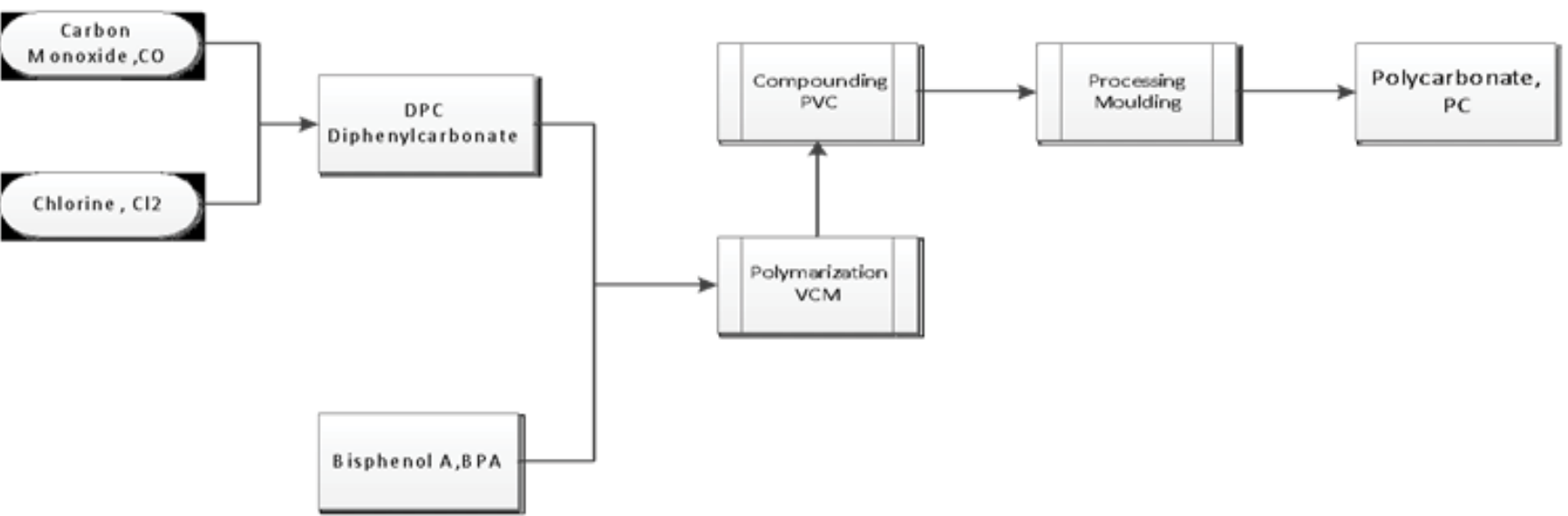

Figure 6: Non-phosgene process. Source: Castro, Jablansky, Lee, and MacMillan ((Adopted) “New Phosgene-Free Route To Polycarbonate”, April 2013).

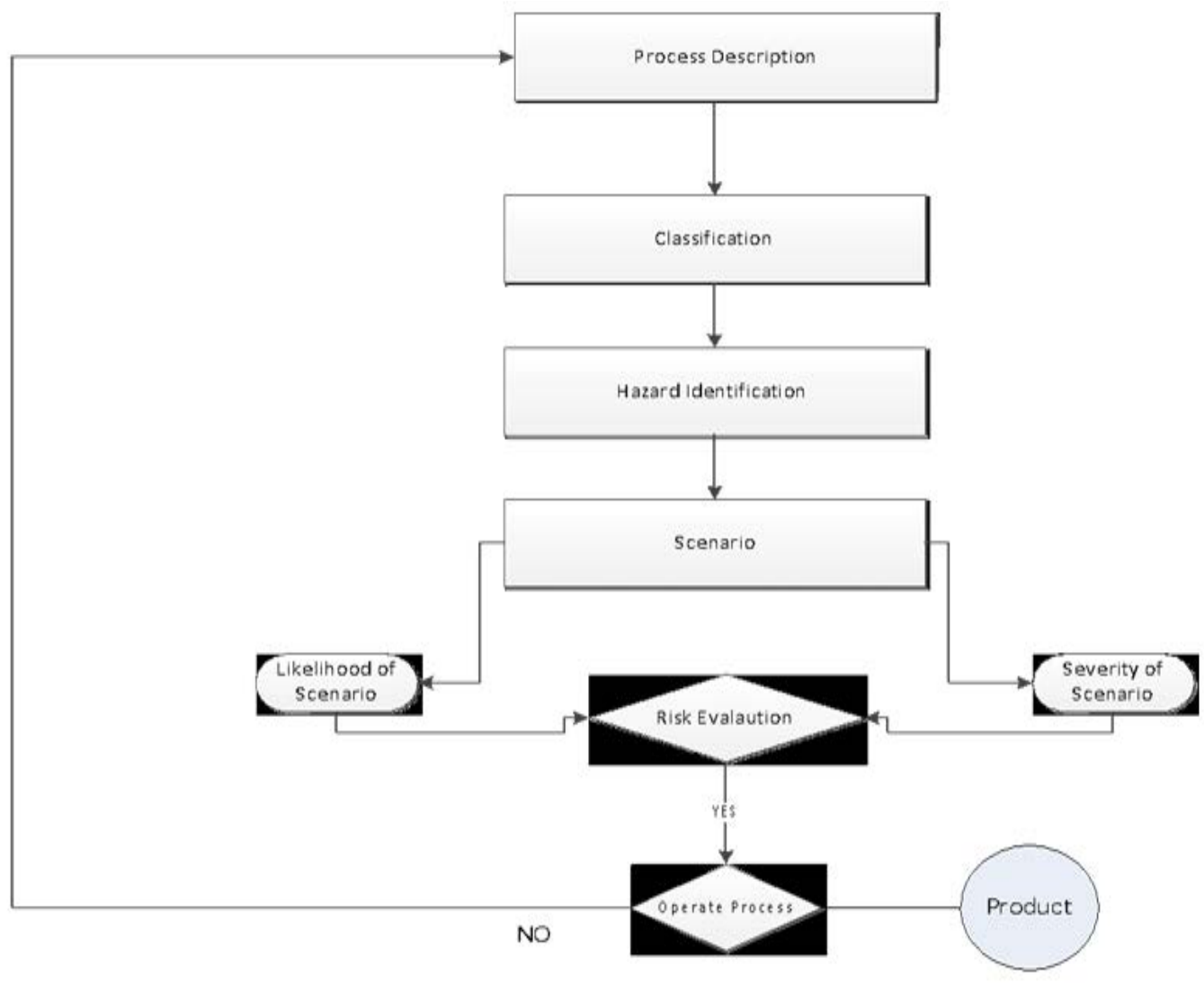

Figure 7: Framework for environmental performance evaluation. 


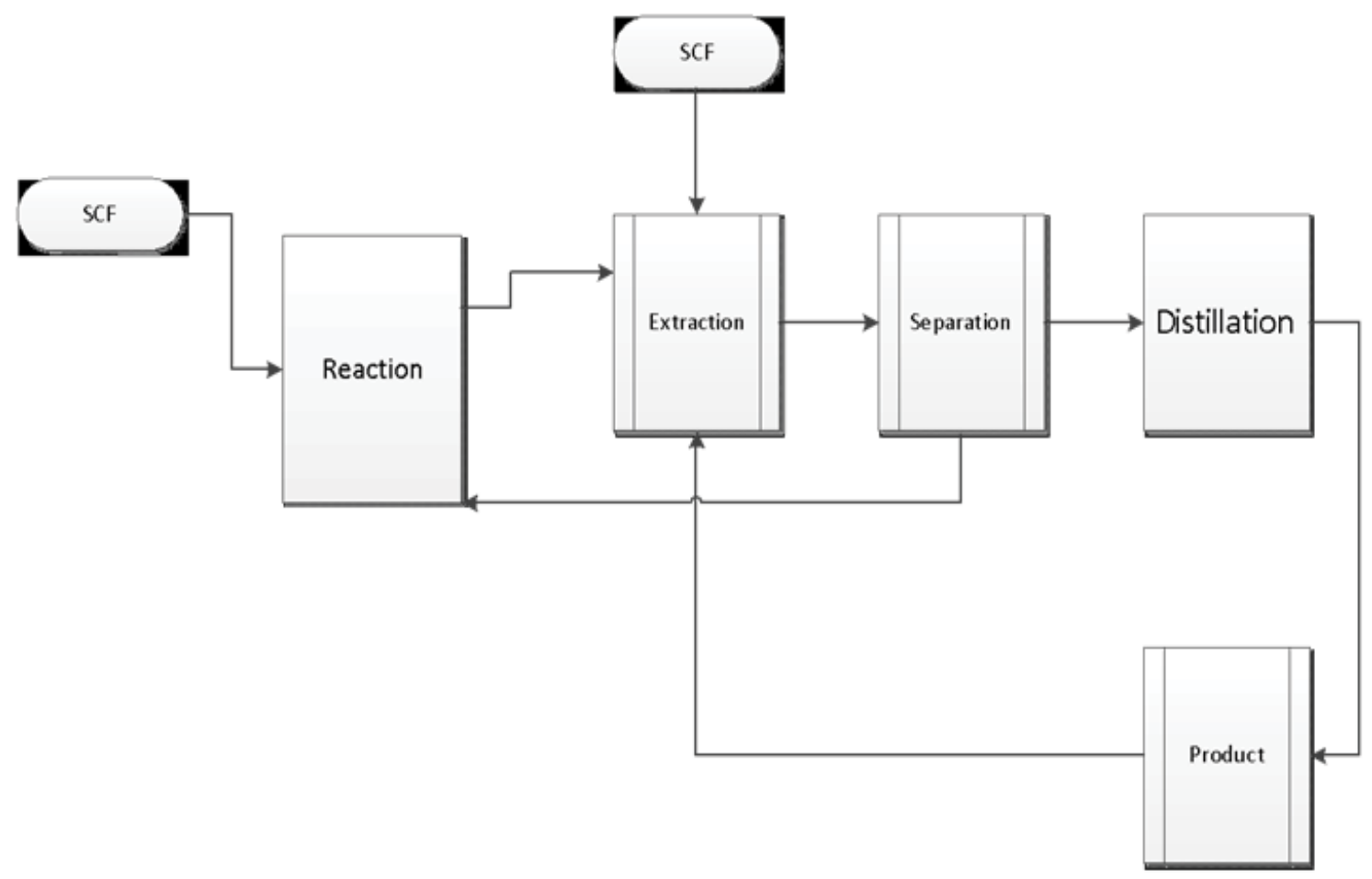

Figure 8: Modified process for PC production.

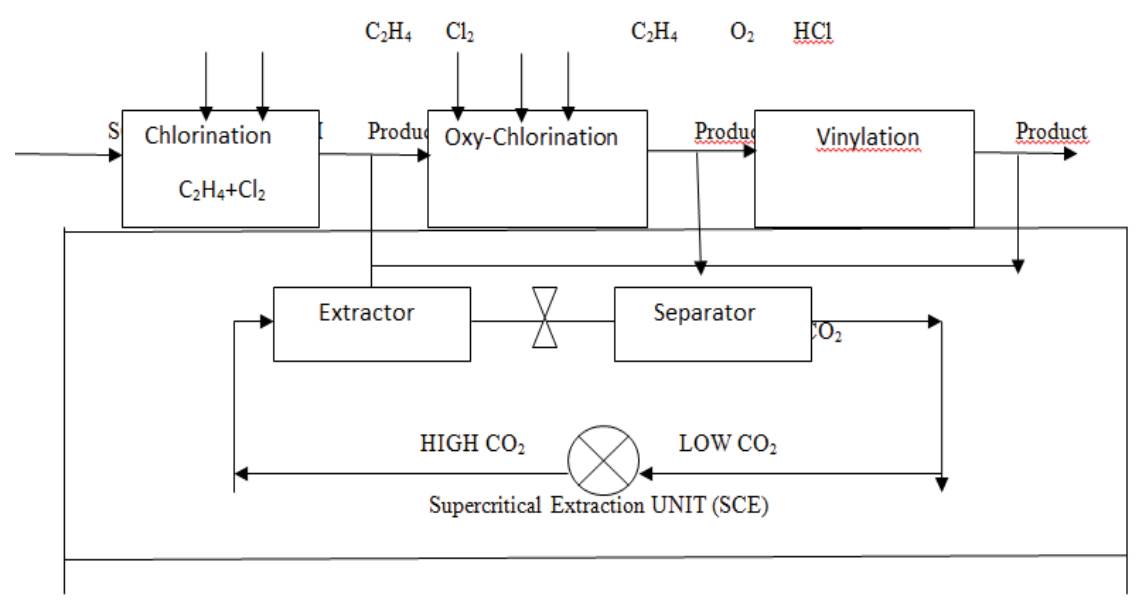

Figure 9: Alternative process diagram.

controlled by selection of suitable pressure/temperature combination. It has a convenient critical temperature $\left(31.04^{\circ} \mathrm{C}\right)$. This enables extractions to be carried out at comparatively low temperature (often as low as 40 or $50^{\circ} \mathrm{C}$ ), decreasing the risk of damage of thermalabile compounds. Most of the volatile components, which tend to be lost in hydrodistillation, are present in the supercritical extracts [18]. Partly because of this, extracts obtained in this way tend to have flavour and taste, which are well liked by tasty panels. Extraction of natural raw material with supercritical $\mathrm{CO}_{2}$, allows the obtaining of extracts which flavour and taste are perfectly respected and reproducible. The supercritical fluid ability to vaporise non-volatile components (at moderate temperatures) reduces the $\mathrm{r}$ energy spent, when comparing to distillation. Once the pressure excess in the equipment prevents oxygen entry while extraction occurs, oxidation reactions don't happen. Also the number of solvents possible to be used on supercritical extraction is superior of classic organic solvents. The last but not least, supercritical fluids have a superior selectivity although they have an inferior solvent power than classic organic solvents.

\section{Application of Methodology to Supercritical Technology}

The process of EDC to VCM produced during three stages, Chlorination, Oxy-Chlorination, and Vinylation steps. The material 
balance for each stage produced various by-products or/and undesired materials through several reactions (1), (2), and (3).

\section{Result and Discussion}

The Data in Table 2 shows that chlorine fraction increased with the increase amount of ethylene $\left(\mathrm{C}_{2} \mathrm{H}_{4}\right)$, thus, increase the ration of the reactants $\left(\mathrm{C}_{2} \mathrm{H}_{4}\right.$ to $\left.\mathrm{Cl}_{2}\right)$ is not necessarily the best optimization to increase the yield. Consequently, more choline will be released. The data described the best production scenario based on the fixed chlorine and different amount of ethylene. Although at increasing ethylene there are more yield achieved, chlorine released also increased. However, scenario one gives the best option among other scenarios based on the $\mathrm{Cl}_{2}$ emission. Environmentally, the lower the emissions, the less impact on human health and environment (Figures 11, 12 and Table 3).

Figures 11 and 12 describe the fate of the reactants during the reaction conversion. Figure 11 shows the increasing rate of ethylene conversion into the production formation of desired product. However, Figure 12 shows the different scenarios of rate of conversion based on the chlorine releases to form the desired product where chlorine slightly increases with the increase conversion. The environmental evaluation goal of emission reduction was achieved as shown in scenario 2 .

\section{Comparison of processes performance}

Table 4 shows the comparison between three methods for polycarbonate production (Chemicals Release due to polycarbonate production by $\mathrm{PVC}, \mathrm{PE}$, and $\mathrm{SCF}$ ). The effect of the production emissions reduction due to Polyethylene (PE) compared with PVC has improved but modified process SCF has given higher emission

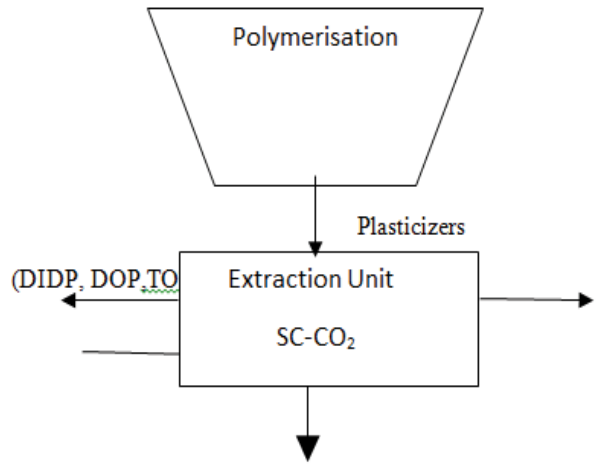

Figure 10: Extraction stage by supercritical fluid.

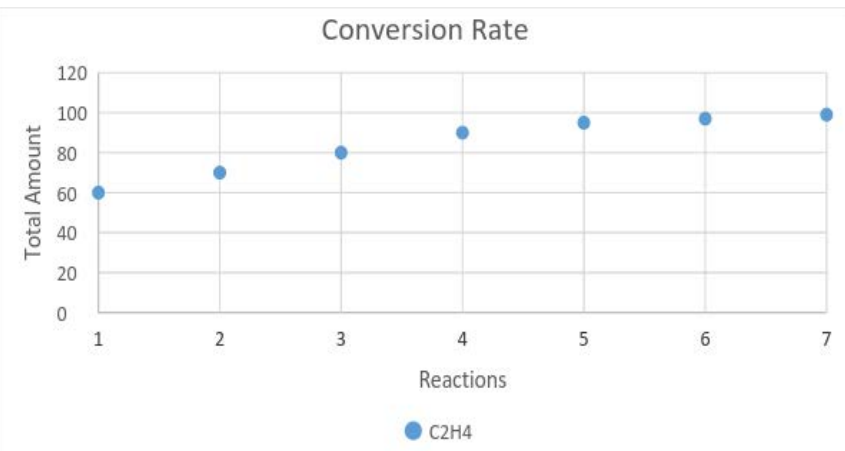

Figure 11: The curve of ethylene conversion reduction by zero Ozone depletion potential without any traces. SCF due to its cost and most importantly is environmentally benign; it is a promising technology for future.

\section{Environmental parameters dispersion model}

ECF will be calculated based on cumulative exposure modeling (Dispersion Model) as follows,

$$
\mathrm{EEC}=0.81 * \mathrm{PD} / \text { tons } \mathrm{NO}_{\mathrm{x} \text { eq. }}
$$

EEC is in units of person ${ }^{\star} \mathrm{hrs}^{\star} \mathrm{ppm} \mathrm{O}_{3} /$ tons $\mathrm{NO}_{\mathrm{x} \mathrm{eq}}$

$\mathrm{PD}$ is the average population density (person $/ \mathrm{km}^{2}$ )

CRF represents the severity of additional risk from accumulative exposure to ozone concentration. Then,

$$
\mathrm{ECF}=\mathrm{EEC}{ }^{*} \mathrm{CRF}
$$

It means that the scale of 0 to 1 is the level of the toxic chemical where the ECF for toxic chemical must be equal 1.

\section{Scenarios}

The scenarios based on the density of population,

1 - Scenario is the rural area for around 100 people/ $\mathrm{km} 2$

2- Scenario is the Urbanised area for around 500 people/ $\mathrm{km} 2$

3- Scenario is the Built up area for around $1000-5000$ people/ $\mathrm{km} 2$

4- Scenario is the City-Centre area for around more than 10000 people/ $\mathrm{km}^{2}$

The following model shows the effect of the process on the different areas or regions based on the density of people (Figure 13).

\section{Environmental impacts of supercritical fluid SCF}

Environmental factor or ECF is either 0 or 1 , if it is 1 then a route of exposure to species is occurring but if it is 0 then there is no exposure

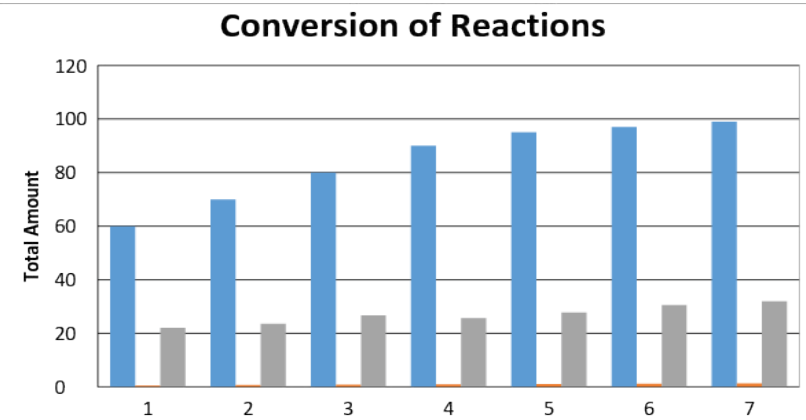

Figure 12: Conversion rate of reaction.

\begin{tabular}{|c|c|c|c|c|c|c|}
\hline Option & $\mathbf{C}_{\mathbf{2}} \mathbf{H}_{\mathbf{4}}$ & $\mathbf{C l}_{2}$ & EDC & Fraction $\mathbf{C l}_{2}$ & \%Conversion & \% Yield \\
\hline 1 & 60 & 30 & 40 & 0.557 & 22.02 & 66.67 \\
\hline 2 & 70 & 30 & 50 & 0.696 & 23.61 & 71.42 \\
\hline 3 & 80 & 30 & 65 & 0.9 & 26.77 & 81.25 \\
\hline 4 & 90 & 30 & 70 & 0.975 & 25.66 & 77.78 \\
\hline 5 & 95 & 30 & 80 & 1.11 & 27.82 & 84.2 \\
\hline 6 & 97 & 30 & 90 & 1.25 & 30.62 & 92.78 \\
\hline 7 & 99 & 30 & 96 & 1.33 & 32.01 & 96.96 \\
\hline
\end{tabular}

Table 3: Conversion rate of the chlorination reaction. 
Citation: Altuwair IB (2017) Environmental Performance Evaluation of Polycarbonates Production Processes. Ind Eng Manage 6: 214. doi:10.4172/2169-0316.1000214

Page 10 of 11

\begin{tabular}{|c|c|c|c|c|c|c|c|c|}
\hline Raw Material, kg & EEC & PVC & CRF & ECF Impact & PE & EEC & ECF Impact & SCF Impact \\
\hline Air & 3.7E-2 & 2175 & 1.0 & $3.7 \mathrm{E}+2$ & 2175 & 3.7E-2 & $3.7 \mathrm{E}-2$ & $3.7 \mathrm{E}-2$ \\
\hline $\mathrm{C}_{2} \mathrm{H}_{4} \mathrm{O}$ & 91.21 & 0.888 & 1.0 & 91.21 & 0 & 0 & 0 & 0 \\
\hline Aldehyde & $2.0 \mathrm{E}+4$ & 3.98E-03 & 1.0 & $2.0 \mathrm{E}+4$ & 0 & 0 & 0 & 0 \\
\hline Water & $9.38 \mathrm{E}+2$ & 8.6E-2 & 1.0 & $9.38 \mathrm{E}+2$ & 2.35E-02 & $3.4 \mathrm{E}+3$ & $3.4 \mathrm{E}+3$ & 0 \\
\hline Alcohol & $8.7 \mathrm{E}+3$ & $9.29 \mathrm{E}-03$ & 1.0 & $8.7 \mathrm{E}+3$ & 2.99E-02 & $2.7 \mathrm{E}+3$ & $2.7 \mathrm{E}+3$ & $2 . E+3$ \\
\hline 1,2-dichloroethane (DCE) & $1.6 \mathrm{E}+3$ & 0.05 & 1.0 & $1.6 \mathrm{E}+3$ & 9.E-3 & $8.99 E+3$ & $8.99 E+3$ & $8.99 E+3$ \\
\hline $\mathrm{CO}$ & $3.7 \mathrm{E}+3$ & 2.1E-2 & 1.0 & $3.7 \mathrm{E}+3$ & 0 & 0 & 0 & 0 \\
\hline $\mathrm{CO}_{2}$ & $1.25 E+2$ & $6.4 \mathrm{E}-1$ & 1.0 & $1.25 \mathrm{E}+2$ & 0 & 0 & 0 & 0 \\
\hline $\mathrm{Cl}_{2}$ & $1.28 \mathrm{E}+2$ & $6.3 \mathrm{E}-1$ & 1.0 & $1.28 \mathrm{E}+2$ & 0 & 0 & 0 & $1.28 \mathrm{E}+2$ \\
\hline $\mathrm{F}$ & 0 & 0 & 1.0 & 0 & 0 & 0 & 0 & 0 \\
\hline $\mathrm{HCl}$ & 49.63 & 1.632 & 6.2 & $3.0 \mathrm{E}+2$ & 0 & 0 & 0 & 49.63 \\
\hline $\mathrm{N}_{2}$ & 99.79 & 0.8117 & 1.0 & 99.79 & 0 & 0 & 0 & 0 \\
\hline $\mathrm{NO}_{\mathrm{x}}$ & 0 & 0 & 0.86 & 0 & 0 & 0 & 0 & 0 \\
\hline EG & $1.62 E+3$ & 0.05 & 1.0 & $1.6 E+3$ & 1 & 81 & 81 & 0 \\
\hline EDC & 15.94 & 5.08 & 1.0 & 15.94 & 5.00E-02 & $1.6 \mathrm{E}+3$ & $1.6 \mathrm{E}+3$ & 0 \\
\hline Hydrocarbons & 0 & 0 & 1.0 & 0 & 1.13E-03 & $7.2 \mathrm{E}+4$ & $7.2 \mathrm{E}+4$ & 0 \\
\hline Vinyl Chloride & 81 & 1.0 & 1.0 & 81 & $9.00 \mathrm{E}-03$ & $9 \mathrm{E}+3$ & $9 \mathrm{E}+3$ & 0 \\
\hline $\mathrm{C}_{2} \mathrm{H}_{4}$ & $1.68 \mathrm{E}+4$ & $4.7 \mathrm{E}-3$ & 1.0 & $1.6 \mathrm{E}+4$ & 0 & 0 & 0 & 16885 \\
\hline Acetylene & 16200 & $5.0 \mathrm{E}-3$ & 1.0 & $1.6 \mathrm{E}+4$ & 0 & 0 & 0 & 0 \\
\hline Catalyst $\mathrm{Cu}^{+}$ & 60 & 1.35 & 1.0 & 60 & 0 & 0 & 0 & 60 \\
\hline BUTD & $1.6 \mathrm{E}+4$ & $5.0 \mathrm{E}-3$ & 1.0 & $1.6 \mathrm{E}+4$ & 9E-03 & $9 \mathrm{E}+3$ & $9 \mathrm{E}+3$ & 0 \\
\hline PVC & 85.26 & $9.5 \mathrm{E}-1$ & 1.0 & 85.26 & 0 & 0 & 0 & 85.0263 \\
\hline $\mathrm{CCl}_{4}$ & $1.6 \mathrm{E}+4$ & $5 E-03$ & 1.0 & $1.6 \mathrm{E}+4$ & 0 & 0 & 0 & 0 \\
\hline TCE & $3.2 E+4$ & $2.5 \mathrm{E}-03$ & 1.0 & $3.2 E+4$ & 0 & 0 & 0 & 0 \\
\hline TRI & $3.2 \mathrm{E}+4$ & $2.5 \mathrm{E}-03$ & 1.0 & $3.2 \mathrm{E}+4$ & 0 & 0 & 0 & 0 \\
\hline CLAL & $3.2 E+4$ & $2.50 \mathrm{E}-03$ & 1.0 & $3.2 E+4$ & 0 & 0 & 0 & 0 \\
\hline TCM & 0 & 0 & 1.0 & 0 & $3.0 \mathrm{E}-2$ & $2.5 \mathrm{E}+3$ & $2.5 E+3$ & 0 \\
\hline Polyethylene & 0 & 0 & 1.0 & 0 & $9.70 \mathrm{E}-01$ & 83.50 & 83.50 & 83.05 \\
\hline ETCL & $3.2 \mathrm{E}+3$ & $2.50 \mathrm{E}-03$ & 1.0 & $3.2 \mathrm{E}+3$ & 0 & 0 & 0 & 0 \\
\hline TEC & $3.2 E+3$ & $2.50 \mathrm{E}-02$ & 1.0 & $3.2 E+3$ & 0 & 0 & 0 & 0 \\
\hline Heavies & $4.6 \mathrm{E}+4$ & 0.0175 & 1.0 & $4.6 \mathrm{E}+4$ & 0 & 0 & 0 & 0 \\
\hline Total Impact & & & & 240954 & & & 109491 & 28949 \\
\hline
\end{tabular}

Table 4: Comparison of different methods of polycarbonate production.

\section{Total Impacts}

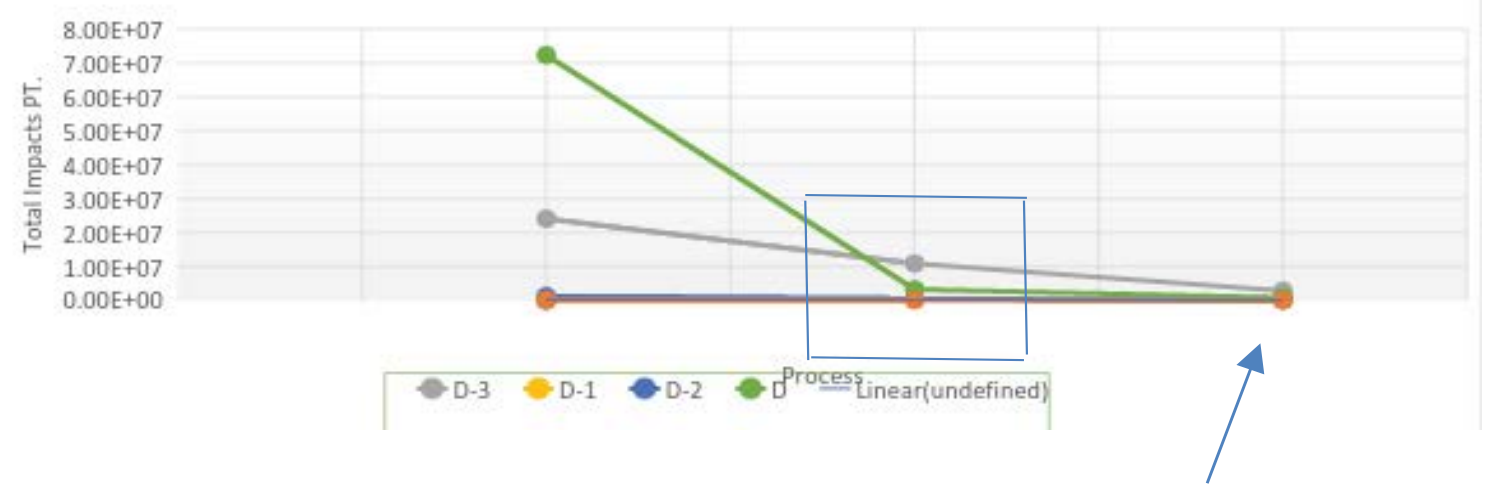

Figure 13: The effect of scenarios modified process.

is occurring, therefore, no environmental impact will be exist from a particular indicator (Figure 14).

The results, shown in Table 1 for parameters distribution, have been modified by supercritical fluid SCF. The indicator of 1 to 0 means that uncertainty is exist among different parameters where 1 scale means $100 \%$ which is not applicable measurement and 0 means $0 \%$ effect. The ozone depletion potential has been reduced to zero effect due to the higher efficiency of the SCF which is proved that there is no any precursors been detected after using SCF. However, Global warming shows that indicator has 1 scale but with less impact on the 


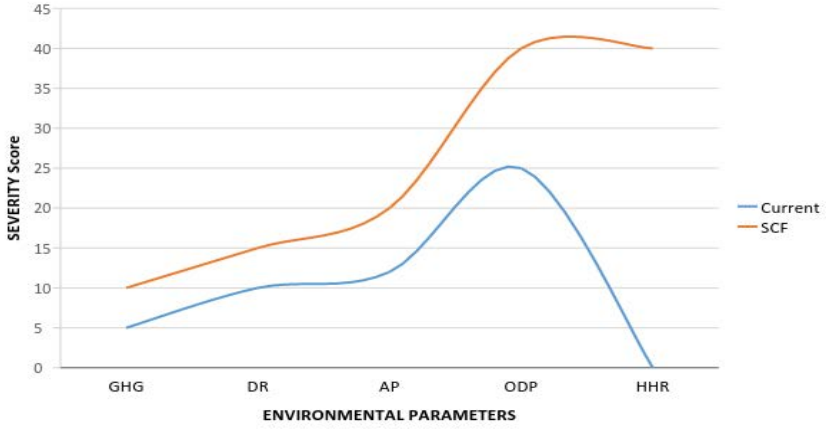

Figure 14: The environmental parameters assessment of polycarbonate productions.

environment due to the application of SCF where uncertainty of the scale of 1 is not necessarily means $100 \%$. Although acidification and eutrophication have been scaled by 1 but their effect measured as low and medium respectively. Furthermore, Figure 14 described the fate of the production processes of polycarbonate where the impact of the environmental parameters resulted from SCF were minimal. In addition, it is shown that the reduction of the environmental impact due to ozone depletion potential (OZP) has been reduced by $100 \%$ therefore the impact of precursor such as CFC, Halons, NOx, VOC, and $\mathrm{CH}_{3} \mathrm{Br}$ been shown 0 impacts. However, accumulation impacts for chemicals resulted from traditional processes were seen at higher and medium levels but it goes to lower potential level when supercritical technology applied. Although indicators that measure environmental efficiency are being developed by institutions and organizations, an indicator that can be commonly used has not been developed yet which might be the source of errors ; however, it is necessary to develop indicators of environmental efficiency which can be commonly use.

\section{Conclusion and Recommendation}

In this paper, traditional processing and alternative modified methods for polycarbonate production were described and compared in terms of environmental performance evaluation (PEP) to identifying opportunities to improve environmental performance of polycarbonate production processes. The advantage of the comparison over the traditional processes route selection is the ability to acknowledge uncertainity and the use of environmental parameters (EP's) calculation. In addition, the influence of modeling analysis and their variation were investigated In order to understand the extent of uncertainty due to undesired products migration in polycarbonate products, amount of toxic materials in polycarbonate (PVC) products have been investigated. It was observed that mass balance method demonstrates the ability of supercritical fluid to eliminate toxic chemical. Results show that higher efficiency can be achieved by SCF. Although this approach is also inexpensive and environmentally benign, more investigations and studies on the plasticising stage, where toxic chemicals released, are recommended. Furthermore, accurate and precise environmental parameters (PE's) are important since the use of indicators is extremely limited, and they need to be further developed otherwise industrial development will continue creating costs in the form of risks of the environment and public health, unless urgent action is taken.

\section{References}

1. Scaife P, Nunn J (2002) LCA Perspective Institute of Japan (42), 5.

2. Khan F, Sadiq R,Veitch B (2004) Life Cycle Index (Linx): a new indexing procedure for process and product design and decision-making. Journal of Cleaner Production 12: 59-76.

3. Sharp RM, Irvine DS (2004) How strong is the evidence of a link between environmental chemicals and adverse effects on human reproductive health. BMJ 328: 447-451.

4. Xu H, Zhang C (2007) Research of LCA Application (10), 33

5. Lin X (1998) Polenske Input-Output modelling of production processes 9: 25 .

6. Cave S, Edwards D (1997) Chemical process route selection based on assessment of inherent environmental hazard. Computers \& Chemical Engineering 21: 965-970.

7. Fava J, Denison R, Jones B, Curran M, Vigon B, et al. (1991) A technical Framework for Life Cycle Assessment" SETAC and SETAC Foundation for Environmental Education. Washinton DC.

8. Pennington D (1997) A pollution Prevention tool for Continuous Chemical Process, Hong Kong University of Science and technology. Hong Kong.

9. Wenzel H, Hauschild M, Alting L (1997) Environmental assessment of Product. In: Wolnik C, Fischer P (eds.) Advancing Pollution Prevention and Cleaner Production, Canada's contribution. Journal of Cleaner Production 14(6): 539-541.

10. Steen B (1999) A systematic approach to Environmental Strategies in Product development (EPS), Version 2000-General System Characteristics. Chalmers University of Technology.

11. Guldbrandsson F, Bergmark P (2013) Opportunities and Limitations of Using Life Cycle Assessment Methodology in the ICT Sector. Ericsson AB, Stockholm, Sweden

12. Shokravi S, Smith A (2012) Industrial Environmental Performance Evaluation International Environmental Modelling and Software Society.

13. Xiu CH, Li HQ, Zhang Y (2008) Integrated Assessment on Pollution Contribution in Iron and Steel Manufacturing Process 21(3): 207.

14. Castro, Jablansky, Lee, Mac Millan (2013) New Phosgene-Free Route to Polycarbonate.

15. Shinsuke F, Isaburo F, Masahiro T, Kazuhiro O, Hiroshi H, et al. (2010) A Novel Non-Phosgene Process for Polycarbonate Production from CO2: Green and Sustainable Chemistry in Practice. Catalysis Surveys from Asia 14: 146-163.

16. Sutherland J, Haapala K (2007) Optimization of steel production to improve life cycle environmental performance. CIRP Annals 56 (1): 5.

17. Sapkale GN, Patil SM, Surwase US, Bhatbhage PK (2010) Supercritical Fluid Extraction. Department of pharmacy, Patil Collage of Pharmacy, Osmanabad.

18. Martinez de La Ossa (1991) Advantages and Disadvantages of Extraction with Supercritical $\mathrm{CO}_{2}$. 